\title{
$\mathrm{Ni}_{3} \mathrm{Al}$-Based Intermetallic Alloys as a New Type of High-Temperature and Wear-Resistant Materials
}

\author{
Karin Gong ${ }^{1}$, LUO He-li ${ }^{2}$, Feng $\mathrm{Di}^{2}{ }^{2}$, LI Chang-hai ${ }^{1}$ \\ (1.Dept. of Materials and Manufacturing Technology, Chalmers University of Technology, Sweden; \\ 2. Central Iron and Steel Research Institute, China)
}

\begin{abstract}
Some intermetallics as high-temperature wear-resistant materials attracted attention of material researchers due to their intrinsic long-range ordered crystalline structures with strong oriented atomic bonding. In the group, $\mathrm{Ni}_{3} \mathrm{Al}$-based intermetallic alloys are especially interesting for certain tribological applications. In this work, the wear-behaviour of an existed $\mathrm{Ni}_{3} \mathrm{Al}$-based alloy, $77.7 \mathrm{Ni}-9.8 \mathrm{Al}-11.5 \mathrm{Fe}-0.5 \mathrm{Mn}-0.5 \mathrm{Ti}-0.1 \mathrm{~B}$ in weight percentage, and its composites reinforced by $\mathrm{Cr}_{3} \mathrm{C}_{2}$-particles were studied, and related to their microstructures. HIPing and casting processes were applied for preparing the materials. Wear-rate of the testing materials under different loads and their scuffing resistance were measured by Pin-on-Disk method. The tested materials were analysed by SEM, EDS, and XRD techniques. The results revealed that the single phase $\mathrm{Ni}_{3} \mathrm{Al}$-based alloy showed a reasonable wear-resistance, compared to a duplex microstructure. And, the investigation also indicated that the hard $\mathrm{Cr}$-carbide played a positive role on tribological intermetallics, especially for reducing the wear-rate.
\end{abstract}

Key words: intermetallics, nickel aluminides, wear-resistant materials.

\section{Technical Background}

It has long been recognized that the tribological behavior of materials plays an important role for the performance of internal combustion engines in terms of power loss, fuel consumption, oil consumption, blow-by and harmful exhaust emission. For most of the last century, research and development in tribology have been directed at meeting the severe conditions of mechanical systems, such as advanced engines, that require increasingly high working temperatures; pressure; and running speeds. Therefore, there is a great interest to explore new materials and manufacturing methods for wear-resistant material and coatings for low-friction and wear-resistant cylinder liners and piston rings.

Cast irons are traditional and unique wear resistant materials that can be used in a range of applications. However, for the engine components like piston rings which are running under a marginal lubrication, only the compacted graphite iron is suitable. Unfortunately, the low strength level of cast irons limits their applications in modem engines.

Metal-matrix composites are attracting interest because of their superior mechanical and tribological properties. For the metal-matrix composites containing hard particles, it has be also recognized that sliding against a metal counter face results in generation of metal filings due to micro cutting; these filings are then compacted during sliding to form a transfer layer. Lubrication could help to avoid this problem. However, this is unfortunately not the case for a marginal lubrication condition of some engine components. Ceramics and ceramic-matrix composites usually show excellent tribological properties, very low friction coefficient and wear rate. But, their intrinsic brittleness and sensitivity to tensile strain and stress impact limit their applications, especially for moving part in engine subjected to wear impact.

Recently, some intermetallics as high-temperature wear-resistant materials attracted attention of material 
researchers and end-users. The main driving force for research into intermetallics has in the past been their attraction for high temperature structural applications. It is only in a few of cases that their tribological properties have been studied. But, there is ample scope in this area for fruitful future research based on:

(1) The intermetallics have long-range ordered crystalline structures with strong oriented atomic bonding, which should be considered as a benefit to a slow wearing rate of the materials.

(2) The intermetallics normally show strong strain-hardenability and yield strength, even the strength is increased with temperature raised up until a certain level. In certain cases, these properties lead to excellent tribological properties under a certain temperature range.

(3) Many intermetallic compounds have low rates of unlubricated sliding wear, which are associated with the strong propensity to chemisorptions of atmospheric oxygen in the compounds. This is especially true that the sliding process was going on under low loads.

In the group of intermetallics, $\mathrm{Ni}_{3} \mathrm{Al}$-based intermetallic alloys are especially interesting for certain tribological applications. In fact, a number of laboratory studies have indicated that $\mathrm{Ni}_{3} \mathrm{Al}$-based alloys have significant potential in wear-critical applications, especially in cavitation erosion and in sliding wear at temperature range between $400^{\circ} \mathrm{C}$ and $650^{\circ} \mathrm{C}[1-6]$. From our earlier work [7], it was also noticed that the $\mathrm{Ni}_{3} \mathrm{Al}$-based alloys are most hopeful as a new kind of high-strength wear-resistant materials under high-temperature.

\section{Experimental Results}

\subsection{Testing materials and preparation}

An iron-alloyed $\mathrm{Ni}_{3} \mathrm{Al}$ (NAC-alloy) was selected in this study. The composition of the alloy is $\mathrm{Ni}-18.8 \mathrm{Al}-10.7 \mathrm{Fe}-0.5 \mathrm{Mn}-0.5 \mathrm{Ti}-0.2 \mathrm{~B}$ in atomic percentage. The monolithic NAC-alloy and its $\mathrm{Cr}_{3} \mathrm{C}_{2}$-reinforced composites were studied by wear test. Marks of the tested samples are summarized in Table 1.
Table 1. Tested materials

\begin{tabular}{|c|c|c|}
\hline Marks & Composition & Process \\
\hline Specimen 1 & NAC-alloy & HIPing \\
\hline Specimen 2 & NAC-alloy + & HIPing \\
& 6 ool.\% coarse & \\
& $\mathrm{Cr}_{3} \mathrm{C}_{2}$ particles & \\
\hline Specimen 3* & NAC-alloy + & HIPing \\
& 6 vol.\% fine Cr $\mathrm{C}_{2}$ & \\
& particles & \\
\hline Specimen 4" & NAC-alloy & As-cast \\
\hline
\end{tabular}

The powders of NAC-alloy were prepared by using Plasma-Rotating-Electrode-Process (PREP) equipment in the Central Iron and Steel Research Institute (CISRI), Beijing. The powder particles are nearly perfect-spherical and mostly distributed in a range of $45-100 \mu \mathrm{m}$.

The tested bulk-materials $1^{\#}, 2^{\#}$ and $3^{*}$ were produced by HIPing process in a Swedish company, Bodytcote. To prepare the composites, coarse particles of $\mathrm{Cr}_{3} \mathrm{C}_{2}$ in a range of $45-90 \mu \mathrm{m}$ and fine $\mathrm{Cr}_{3} \mathrm{C}_{2}$-particles less than $45 \mu \mathrm{m}$ were used. The temperature $1130-1160^{\circ} \mathrm{C}$, pressure $100 \mathrm{MPa}$ and time 3 hours are applied during HIPing process.

As-cast bulk material $4^{\#}$ for testing were prepared by CISRI using a vacuum $\left(33 \times 10^{-2} \mathrm{~Pa}\right)$ induction melt furnace. The holding temperature of melt is $1550^{\circ} \mathrm{C}$. And, the pouring temperature is $1460^{\circ} \mathrm{C}$ for the vacuum investment casting into a ceramic shell.

\subsection{Wear Test}

Pin-on-Disk tests under the different loads were carried out in this work. The tested materials were machined to be pins with dimension as $\Phi 8 \times 25 \mathrm{~mm}$. The disk material is a standard Tarkalloy-C cast iron which is usually used as the material for cylinder liner. The applied pressures on the pins were $8.6 \mathrm{bar}, 17.2 \mathrm{bar}$, and 34.4 bar, respectively. 3 pins of each listed material were tested under the determined loads. The wear loss of the pins for the sliding distances of 5,000 and 20,000 meters were measured. The typical results of steady specific wear rate $\left(\mathrm{mm}^{3} / \mathrm{mm} \cdot \mathrm{N}\right)$ under one load $(17.2$ 
bars) from the specimens $1^{\#}, 2^{*}$ and $3^{*}$ and Darcast cast-iron, as a reference material, are given in Fig.1. The Darcast is a compacted graphite cast iron and widely used as a wear-resistant material in industries with a reasonable strength level.

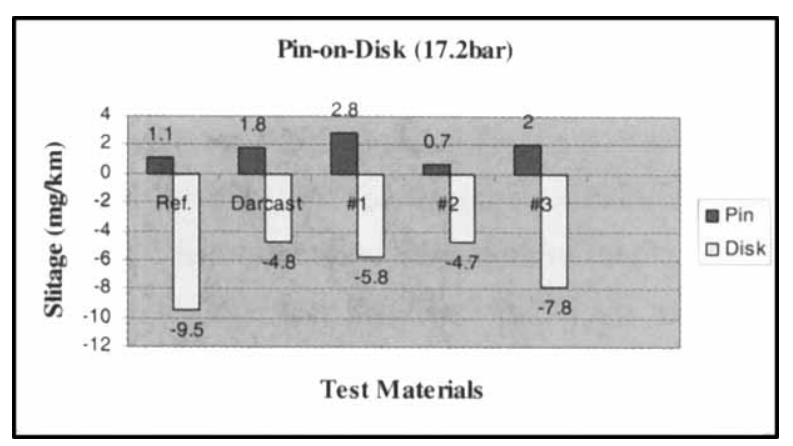

Fig.1 Specific wear rate $\left(\mathrm{mm}^{3} / \mathrm{mm} \cdot \mathrm{N}\right)$ under one loads of 17.2 bar from the specimens $1^{\#}, 2^{\#}, 3^{\#}$ and darcast cast-iron, $\mathrm{Ni}$-superalloying as two reference materials

From the figure 1 it can be recognized that the wear loss rate of the tested intermetallic specimens $1^{\#}$, $2^{*}$ and $3^{*}$ showed rather good wear resistance, compared to the Darcast material. For the intermetallic specimens comparatively, the sample $2^{\#}$ with the coarse carbide reinforcement has the best wear resistance in the group under the applied load. The composite $3^{*}$ reinforced by the fine $\mathrm{Cr}_{3} \mathrm{C}_{2}$-particles showed a relatively worse wear resistance, but is still better than the monolithic NAC-alloy $1^{\#}$.

Scuffing phenomenon usually appeared when the material is on sliding-wear under a certain high load. The scuffing process is very complicated and resulted in a serious wear-off component. Therefore, scuffing resistance of the tested materials was also investigated by Pin-on-Disk method in this work. The measured data indicated that no scuffing effect was observed on the HIPed intermetallic specimens even under the highest applied pressure of the testing machine, i.e. 220 bar, compared to 150 bars of the as-cast $4^{*}$ specimen and 100 bars of the Darcast specimen.

\subsection{Analytical Experiments}

The backscattering electron image (BEI) of the
HIPed monolithic NAC-alloy, specimen $1^{\#}$, showed a single phase microstructure, and is crack-free and almost no porosity existed. A quantitative analysis by EDS indicated that the composition of the matrix is very close to the composition of the alloy. Fig.2a is a backscattering electron image of specimen $2^{\# \text {, a }}$ composite reinforced by so-called coarse $\mathrm{Cr}_{3} \mathrm{C}_{2}$ particles. It was noticed that the carbide-particles were reacted with the matrix around. An unchanged core is still existed in some big $\mathrm{Cr}_{3} \mathrm{C}_{2}$-particles. Otherwise, the whole particle changed their composition due to the reaction between the particle and matrix, such as observed in the composite $2^{*}$ reinforced by the finer $\mathrm{Cr}_{3} \mathrm{C}_{2}$-particles.

Fig. $2 \mathrm{~b}$ is a backscattering electron image of the as-cast NAC-alloy, specimen $4^{\#}$. A composition contrast of the image indicated that two different phases existed in the material. The diffraction pattern from the specimen $4^{\#}$ clearly revealed that the matrix, as a major phase, has a $\mathrm{Ni}_{3} \mathrm{Al}$-type of crystalline structure, and co-exists with a NiAl-phase.

\section{Discussion}

The wear-rate measurement by Pin-on-Disk in this work revealed that the wear-loss rates of the HIPed NAC-alloy are rather similar to the traditional wear-resistant cast iron under low loads, i.e. 8.6, 17.2, and 34.4 bars. But, the wear-resistant cast iron will run into scuffing under a high load below 100 bars. Comparatively, the HIPed NAC-alloy was even not scuffed under a load of 220 bars; a maximum load can be reached by the test-unit. The excellent wear performance of the tested $\mathrm{Ni}_{3} \mathrm{Al}$-based alloy for high loads is related to its crystalline structure and mechanical properties.

Sliding and adhesive wear refer to a type of wear generated by the sliding of one solid surface along another surface. Adhesive wear denotes a wearing action in which no specific agency can be identified as the cause of the wear. In fact, adhesion is the consequence of contact. Wearing occurs when interfaces in contact are made to slide and the locally 

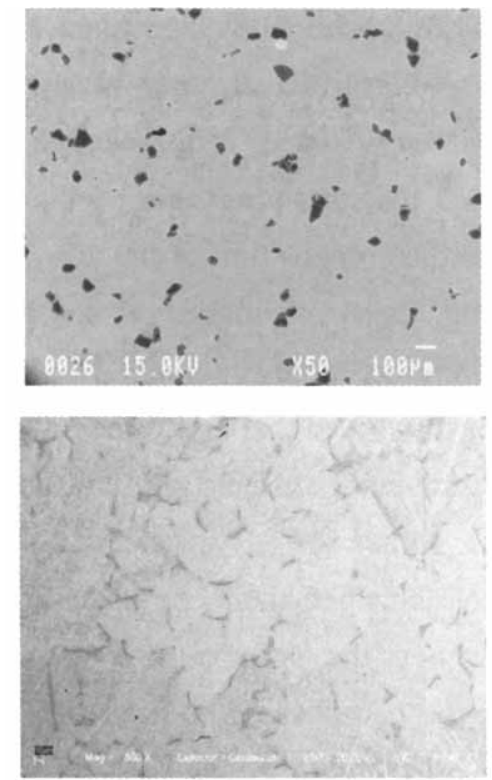

(a)

(b)

Fig.2 (a) BEI of 3\# HIP sample reinforced by Cr-carbide particles; (b) BEI of 4\#casted specimen with unequilibrium duplex phases.

adhered regions must separate. It means that the adhesive wear is concerned with a micro-welding and tearing process. Obviously, the materials of a sliding pair with similar crystal structures could be suffered more seriously to this kind of wearing. The intermetallic materials have long-range ordered crystal structures, which are completely different, compared to the metallic wearing counterpart. The difference on crystal structures will be meaningful for itself and its counterpart to reduce wearing.

It was also known that the ordered $\mathrm{Ni}_{3} \mathrm{Al}$ becomes stronger as temperatures increased in a certain range. And also, the $\mathrm{Ni}_{3} \mathrm{Al}$-based alloys have high work-hardenability. So, the mechanical deformation and frictional heating would create a harder surface region. This character would make $\mathrm{Ni}_{3} \mathrm{Al}$-based alloys resistant to adiabatic shear, and perhaps to shear instability in general. Also, boron doping greatly strengthens grain boundaries of $\mathrm{Ni}_{3} \mathrm{Al}$, improving ductility and fracture toughness. The effect could make the doped material resistant to transfer, and therefore to sliding wear. The studied NAC-alloy also contained
Fe-element. Our earlier works and another study ${ }^{[8]}$ indicated that the addition of iron in the amount not exceeding 11 at. \% contributes to the increase of the mechanical properties mentioned above.

The $\mathrm{Cr}_{3} \mathrm{C}_{2}$-particle reinforced NAC-composites have even better wear-properties; the same level of scuffing resistance and lower wear-rate for the lower loads, compared to the monolithic NAC-alloy. According to the knowledge of tribological behaviours of metal-matrix-composites, it is clear that the wear-loss rates of the particulate reinforced composites are lower than their metallic matrices, because the added hard particles kept the sliding surfaces apart during the wearing process and reduced contribution of adhesion between the sliding surfaces. This is also true for the intermetallic composites studied in this work.

The as-cast NAC-alloy has a lower scuffing load than the HIPed alloy due to its different phase constitution. There are two phases existed in the as-cast alloy: $\mathrm{Ni}_{3} \mathrm{Al}$-matrix and second $\mathrm{NiAl}$-phase, but only one single $\mathrm{Ni}_{3} \mathrm{Al}$-phase in the HIPed alloy. Our earlier work ${ }^{[7]}$ showed that NiAl-based alloy has a worse wear performance than the $\mathrm{Ni}_{3} \mathrm{Al}$-based alloy. The observed phenomenon can be simply understood based on a mixture regulation of these two phases. But, it should be also considered that the fragments of the brittle $\mathrm{NiAl}$-phase as hard particles become embedded in the counter face and causes abrasion.

The reason to form $\mathrm{Ni}_{3} \mathrm{Al}+\mathrm{NiAl}$ microstructure in the as-cast NAC-alloy is the fast cooling rate of the casting process. On the contrary, there is only one $\mathrm{Ni}_{3} \mathrm{Al}$-phase existed in the Hipped alloy, which is related to a slow cooling rate in the HIPed process: the alloy was cooled in a chamber with a low rate from a temperature over $1100^{\circ} \mathrm{C}$ to $500^{\circ} \mathrm{C}$. Obviously, the microstructure of the as-cast alloy is in a un-equilibrium condition.

\section{Conclusions}

As a new type of wear-resistant materials, a Fe-alloyed $\mathrm{Ni}_{3} \mathrm{Al}$ (NAC-alloy) with a composition of $\mathrm{Ni}-18.8 \mathrm{Al}-10.7 \mathrm{Fe}-0.5 \mathrm{Mn}-0.5 \mathrm{Ti}-0.2 \mathrm{~B}$ (at. \%) was 
selected in this study. The tested monolithic NAC-alloy and its $\mathrm{Cr}_{3} \mathrm{C}_{2}$-reinforced composites were prepared by powder metallurgy. The qualified homogeneous testing specimens were obtained. An as-cast NAC-alloy by the vacuum metallurgy and casting process was also prepared in this investigation. The working results indicated:

(1) The studied $\mathrm{Ni}_{3} \mathrm{Al}$-based alloy showed much higher scuffing pressure than the traditional wear-resistant compact cast iron. In general, the promising tribological performance of the studied $\mathrm{Ni}_{3} \mathrm{Al}$-based alloy should be related to its intrinsic crystalline structure and the characters on mechanical properties.

(2) $\mathrm{The} \mathrm{Cr}_{3} \mathrm{C}_{2}$-particle reinforced NAC-composites have even lower wear-rate, compared to the monolithic NAC-alloy, because the added hard particles kept the sliding surfaces apart during the wearing process and reduced contribution of adhesion between the sliding surfaces.

(3) The as-cast NAC-alloy has a lower scuffing load than the HIPed alloy due to the existed NiAl-phase in microstructure. And, a fast cooling rate of the casting process is the reason to course the un-equilibrium $\mathrm{Ni}_{3} \mathrm{Al}+\mathrm{NiAl}$ microstructure in the alloy.

\section{References:}

[1].B. J. Marquardt and J. J. Wert, Proc. Mater. Res. Soc., Vol. 39, 1985, P. 247.

[2].P. J. Blau and C. E. DeVore, J. Tribology, Vol. 110, 1988, P. 646.

[3].N. R. Bonda and D. A. Rigney, Proc. Mater. Res. Vol. 133, 1989, P. 585.

[4].P. J. Blau and C. E. DeVore, Proceedings of the 1989 Wear of Materials Conference, American Society of Mechanical Engineers, 1989, P. 305.

[5].P. J. Blau and C. E. DeVore, Tribol. Ins., Oct. 1990, P. 226.

[6].M. Johnson, D. E. Mikkola, P. A. March, R. N. Wright, Wear, Vol. 140, 1990, P. 279.

[7].J. Rezaie-Haghighi, Master Thesis R938/00, Dept. of Engineering Metals, Chalmers University of Technology, Sweden, 2001.

[8].R. N. Wright, J. R. Knibloe, Acta Metallurgica, Vol. 38, 1990, P. 1993. 